\title{
Method of automatic search for odor-induced patterns in bioelectric activity of a rat olfactory bulb
}

\author{
I. V. Shcherbana, Dr. Sc., Tech., Professor, orcid.org/0000-0002-3997-9151, shcheri@mail.ru \\ P. O. Kosenkoa, PhD, Biol., orcid.org/0000-0002-4333-5332 \\ O. G. Shcherbana, PhD, Tech., Associate Professor, orcid.org/0000-0001-5139-8520 \\ P. V. Lobzenko ${ }^{\text {b }}$ PhD, Tech., Associate Professor, orcid.org/0000-0002-5293-0109 \\ a Southern Federal University, 105/42, B. Sadovaya St., 344006, Rostov-on-Don, Russian Federation \\ bMoscow Technical University of Communications and Informatics, 32, Narodnogo Opolcheniya St., 123423, \\ Moscow, Russian Federation
}

\begin{abstract}
Introduction: The olfactory system in chronic animal experiments is studied according to the records of bioelectric activity recorded with microelectrode arrays located on the dorsal surface of the olfactory bulb. It is believed that the response of the olfactory bulb bioelectric activity to the odorant presentation is associated with fluctuations synchronized by respiration and belonging to the range of so-called gamma rhythms. Purpose: To develop a method of automatic search for time boundaries of odor-induced gamma rhythm patterns in the bioelectric activity of an olfactory bulb. Results: The complexity of automatic search for odor-induced patterns are due to masking them by spontaneous oscillations of gamma rhythms unrelated to the olfactory system activity. Besides, the modal frequency of the patterns is a priori unknown and changes dynamically during an experiment on an anesthetized animal. The Hausdorff distance is used as a cost function of the search. In order to increase its sensitivity, an adaptive band-pass filter was synthesized based on a multichannel singular spectrum analysis. Its passband in the analyzed time sample corresponds best to the spectrum of the required patterns. The results of experiments on rats are presented. The use of band-pass filters based on the Fourier transform with parameters unchanged during the experiment due to the non-stationary nature of the frequency characteristics of the desired patterns does not ensure their effective search. In particular, when using the Butterworth band-pass filter in the search algorithm, significant errors were observed in determining the time boundaries of the epochs of patterns, and omissions of patterns. But the use of a synthesized adaptive band-pass filter provided reliable automatic search for patterns and determination of their time boundaries with a high accuracy. Algorithm failures in this case were observed only in rat motion artifacts. Practical relevance: The developed method extends the existing tools used to study the olfactory system of a living organism.
\end{abstract}

Keywords - olfactory bulb, bioelectric activity, odor-induced patterns, Hausdorff distance, multichannel singular spectrum analysis.

For citation: Shcherban I. V., Kosenko P. O., Shcherban O. G., Lobzenko P. V. Method of automatic search for odor-induced patterns in bioelectric activity of a rat olfactory bulb. Informatsionno-upravliaiushchie sistemy [Information and Control Systems], 2020, no. 5, pp. 62-69. doi:10.31799/1684-8853-2020-5-62-69

\section{Introduction}

Experimental studies of the olfactory system in chronic animal experiments presume the analysis of multidimensional time records of bioelectric activity (BEA) of the olfactory bulb (OB), recorded with microelectrode arrays. The observed BEA reflects the averaged aggregates of synaptic, neuronal, and axonal activities of neuron groups which represent the functioning of the neural network in the volume of tissue [1, 2]. The difficulties of the research in this case are mainly due to the fact that the applicability of the event-related potentials (ERPs), a well-proven method in studying other sensory systems, is fundamentally limited here. Classically, the ERPs method is based on a dogma that there is a certain synchronizing factor, a stimulus label. In experimental studies of the somatosensory, visual or auditory system of a living organism, the time moments of their external influences are known quite accurately. This allows us to reasonably summarize a large number of EEG fragments which immediately follow the presentation of a stimulus, reflecting a weak BEA response from the organism. Thus, averaging the selected epochs by their implementations makes it possible to pick out ERPs components in the EEG against the background of other oscillations unrelated to the BEA response of the sensory system under study.

In the olfactory system, the main synchronizing factor is the moment of inhalation. Normally, respiration is characterized by variability in frequency and depth of inhaling [3]. Respiratory activity patterns affect the temporal structure of the sensory input and subsequent processing in the brain [4], amplifying the modulation of the incoming sensory signals [5]. Such variability, especially taking into account the weak reaction of the olfactory system to a low concentration of odorants makes it impossible to accurately determine the initial moment of the organism's reaction and, thus, to perform multiple summation of the response ERPs. Besides, the latency (duration) of a reaction to the presentation of odorants in the $\mathrm{BEA}$ structures of an OB is still unclear; this reaction is 
determined both by changes in the air concentration of the odorant and by the adaptation of the olfactory system to the presented odorant at different levels of its organization, or by other reasons.

The activation mechanisms and information coding principles used in the olfactory system are not fully understood yet, unlike the other sensory systems. At present, it is generally accepted that an $\mathrm{OB}$, when an odorant is presented, produces a BEA response associated with fast gamma oscillations synchronized with the respiration and related to the frequency range $30-150 \mathrm{~Hz}[1,2,6]$. The difficulties in the automatic search for epochs containing such odor-induced gamma rhythm patterns are caused by the following reasons. The activity pattern has a narrow-band spectrum within $30-150 \mathrm{~Hz}$, and at certain moments of observation the spectrum width can be only 20-35 Hz. Moreover, its modal frequency is not only a priori unknown; it is also not constant, dynamically changing during the experiment, in particular, on an anesthetized animal. The pattern duration is $20-25 \%$ of the respiration period, falling on the final phase of the inhalation, and the amplitude is only $10-30 \%$ of the recorded BEA record amplitude. Thus, odor-induced patterns are masked by other rhythms of a close frequency range which have a significantly higher amplitude, and by spontaneous gamma oscillations of a strong intensity with close frequency spectra.

The existing approaches to solve similar problems of search and time-axis localization of a priori undefined structures of unknown frequency oscillators are well developed. For example, there is a widely used technique which, through windowed Fourier transform, or through discrete or continuous wavelet transforms, turns a temporal representation into a time-frequency one, and runs a search based on various entropy criterion functions. Such methods were used in the problems of identifying the effects of alcohol on EEG [7], assessing cardiac rhythm irregularities by ECG [8], diagnosing epilepsy [9], and others.

However, it is the temporal non-stationarity in the frequency characteristics of gamma rhythm patterns that makes it impossible to use many of the existing approaches for their search. For example, the authors of $[10,11]$ discuss methods which allow you to detect low-intensity gamma oscillations in EEG when their frequency spectra are also unknown and close to the characteristics of the noise components. But the additional criterion functions introduced here in order to select the frequency range most suitable to the spectrum of the sought patterns can be used only if the frequency characteristics of the patterns are stationary over the observation interval.

Therefore, in order to expand the available tools for studying the olfactory system by a recorded
BEA, we need a method of automatic search for the time boundaries of odor-induced gamma rhythm patterns.

\section{Formalization of the problem}

Using the microelectrode array on the dorsal surface of an $\mathrm{OB}$, at time moments $t \in\left[t_{0} ; T\right]$ we record a multidimensional time series of BEA $\mathbf{S}(t)=\left(S_{1}(t)\right.$, $\left.S_{2}(t), \ldots, S_{J}(t)\right)^{\mathrm{T}}$, where $t_{0}$ is the initial moment equal to zero by default; $T$ is the current sampling interval; $J$ is the number of electrodes in array; and ${ }^{\mathrm{T}}$ is a transpose operator. Thus, for a sampling interval $T$ at each $j^{\text {th }}(j=\overline{1, J})$ channel of array, the observed BEA can be presented as a one-dimensional time series $S_{j}(T)=\left\{s_{j, k}\right\}_{k=1}^{K}$ as large as $K=T / \Delta t$ numbers, where $\Delta t$ is the discretization interval. At short time intervals significantly smaller than the sampling interval $T$, the presence of periodic odor-induced BEA is assumed, manifested in the form of low-amplitude patterns. The frequency spectrum of the narrow-band patterns is unknown beforehand; it refers to the range of $30-150 \mathrm{~Hz}$, changing dynamically during the experiment. The problem is to find temporal epochs in the recorded signal which would contain such patterns.

\section{Synthesis of an adaptive narrow-band band-pass filter}

To solve the problem, it is reasonable to use the traditional approach when the search is performed within a certain sliding time window, much smaller than the sampling interval $T$. The criterion function for that should reflect the presence or absence of the desired gamma rhythm patterns in the current window. Apparently, ensuring a sufficient sensitivity of such a function when searching for low-amplitude patterns is possible on the basis of preliminary filtering of multidimensional BEA records in order to select the frequency range of interest. Experimental studies have shown that due to the presence of noise in the BEA records with frequency spectra close to the spectra of the sought patterns, the use of bandpass filters (BPF) with a priori specified parameters does not ensure that the criteria search functions are sensitive enough. In the multidimensional signal $\mathbf{S}(t)$, we need to pick out a narrow frequency range which would most closely match the spectrum of the sought patterns. Besides, it should be taken into account that the synthesized BPF must be adaptable to temporary fluctuations in the frequency characteristics of the sought patterns.

In order to synthesize a BPF that meets the formulated requirements, it is a good idea to apply 
the technique of Singular Spectrum Analysis of time series (SSA), also called "Caterpillar" in its Russian version [12-14] or, in the multidimensional case, MSSA (Multichannel SSA). It allows you to synthesize a set of one low-frequency filter (LFF) and $(M-1)$ linear BPFs. After applying the MSSA technique at a sampling interval $T$ (see Appendix), we can use a set of $M$ filters to split a multidimensional record $\mathbf{S}(T)$ into $M$ time series, so-called reconstructed components (RCs), of the same dimension $J \times N_{k}$ as the original record $\mathbf{S}$ has:

$$
\begin{aligned}
\tilde{\mathbf{S}}_{1}(T) & =\left(\begin{array}{llll}
\tilde{S}_{1,1} & \tilde{S}_{2,1} & \ldots & \tilde{S}_{J, 1}
\end{array}\right)^{\mathrm{T}}, \ldots \\
\tilde{\mathbf{S}}_{M}(T) & =\left(\begin{array}{llll}
\tilde{S}_{1, M} & \tilde{S}_{2, M} & \ldots & \tilde{S}_{J, M}
\end{array}\right)^{\mathrm{T}} .
\end{aligned}
$$

The frequency spectra $\Delta F_{1}, \ldots, \Delta F_{M}$ of the RCs (1) are sorted in ascending order, and the upper boundaries of the spectra satisfy the inequality $f_{1}^{\mathrm{B}} \leq f_{2}^{\mathrm{B}} \leq \cdots \leq f_{M}^{\mathrm{B}}$, where $f_{M}^{\mathrm{B}}=0,5 f_{s} ; f_{s}=1 / \Delta t$ is the sampling frequency. The sum of the narrow-band $\mathrm{RCs}$ is the initial multidimensional time series

$$
\tilde{\mathbf{S}}_{1}(T)+\tilde{\mathbf{S}}_{2}(T)+\ldots+\tilde{\mathbf{S}}_{M}(T)=\mathbf{S}(T) .
$$

Varying the number of filters $M$ leads to changes in their passbands. The frequency spectra $\Delta F_{1}$, ..., $\Delta F_{M}$ of the RCs change in a similar way (1). Therefore, when varying $M$ based on the features of the signal under study and selecting the required RCs (1), we can separate the harmonic components, even those which intersect in the time-frequency space [15-18].

In order to simplify the synthesis of the required $\mathrm{BPF}$, let us restore the narrow-band signal by just one multidimensional reconstructed component $\tilde{\mathbf{S}}_{m}(T) \quad(m=\overline{1, M})$ from (1). In $[12,17,18]$ it is shown that the number $M$ can be constrained by an upper limit $M_{\max } \leq 0,5 N_{k}$. Since it is known that the largest possible width of the sought patterns cannot exceed $35 \mathrm{~Hz}$, we also can find a lower limit $M_{\min }$. The following reasoning will help us reach our goal.

It is known that $M J$ counts of the eigenvector $V_{m}$ of the averaged sample correlation matrix $\mathbf{C}$ (A.2) formed from the trajectory matrix $\mathbf{X}(T)$ (A.1) for $\mathbf{S}(T)$ are $M J$ counts of the impulse response function $h_{m}$ of the non-recursive $m^{\text {th }}(m=\overline{1, M})$ filter [13]. The frequency response $H_{m}$ is a Fourier transform of the impulse response function $H_{m}\left(e^{j 2 \pi f^{\prime}}\right)=\sum_{n=0}^{M J-1} h_{m, n} e^{-j 2 \pi f^{\prime} n}$, where $f^{\prime} \in[0 ; 0,5]$ is a reduced frequency, and the frequency response of this $m^{\text {th }}$ filter is a function of the number of filters $M$ used in the MSSA:

$$
A_{m}=\left|H_{m}\left(e^{j 2 \pi f^{\prime}}\right)\right|=A_{m}\left(f^{\prime}, M\right) .
$$

Since for a given $M$ the width of the effective passband $\Delta F_{m}(M)=f_{m}^{u}-f_{m}^{l}$ is the same for all the BPFs [12-14], where $f_{m}^{u}$ and $f_{m}^{l}$ are the upper and lower cut-off frequencies of the frequency response (3), the value of $M_{\min }$ can be found from the condition

$$
M_{\min }=\underset{M}{\arg \max }\left\{\Delta F_{m}(M) \leq 35\right\} .
$$

With the reduced frequency step $f^{\prime}=1 / f_{s}$ chosen in (3), we can calculate the values of the frequency response $A_{m}(f, M)$ in the actual frequency range $f \in\left[0 ; 0.5 f_{s}\right]$ with $1 \mathrm{~Hz}$ resolution. Thus, when $M$ is selected in the range $M_{\min } \leq M \leq M_{\max }$, the effective passband width of each BPF will approximately correspond to the a priori known width of the gamma activity pattern spectrum.

Due to the fact that the components $S_{1}(T), \ldots$, $S_{J}(T)$ of a multidimensional BEA $\mathbf{S}(T)$ measured on a living organism on $J$ channels in array at the same time moments are produced by the same physiological process, it would be permissible to average the corresponding counts of the power spectrum (PS) for the channels in the frequency range of interest:

$$
\mathbf{P}(f)=\frac{1}{J} \sum_{j=1}^{J} P_{j}(f) ; f \in[30 ; 150] \mathrm{Hz},
$$

where $P_{j}(f)$ are PS values of a one-dimensional signal $\left\{s_{j, k}\right\}_{k=1}^{K}$ for each count of frequency $f$. It should be noted that averaging over $J$ channels of the similar on time $k^{\text {th }}$ counts of the components $\left\{s_{j, k}\right\}_{k=1}^{K}$ with the subsequent calculation of the PS function is incorrect since, as we know, some of the $J$ one-dimensional time series of the BEA can be recorded inverted.

Frequency responses of the BPF (3) have a Gaussian shape [13]. Apparently, for an adaptive BPF, the frequency $f_{m}^{\max }$ corresponding to the maximum of its frequency response $A_{m}^{\max }$ at every moment of the observation should be close to the current modal frequency $f_{\gamma}^{\max }=\underset{f}{\arg \max }\{\mathbf{P}(f) ; 30 \leq f \leq 150\}$ of the sought gamma activity pattern. Hence, the characteristics of the required $m^{\text {th }}$ BPF should be such that the averaged PS function

$$
\tilde{\mathbf{P}}_{m}(f)=\frac{1}{J} \sum_{j=1}^{J} \tilde{P}_{m, j}(f)
$$

of the RC $\tilde{\mathbf{S}}_{m}(T)$ comes nearest to the PS function $\mathbf{P}(f)(4)$, where $f \in[30 ; 150] \mathrm{Hz}$.

Based on the presented reasoning, we can make a final conclusion that if the optimal values of $M_{\mathrm{opt}}$ and $m_{\text {opt }}$ should be chosen from the condition 


$$
\begin{aligned}
\min _{M_{\min } \leq M \leq M_{\max }} & \left\{\sum_{30 \leq f \leq 150}\left[\mathbf{P}(f)-\tilde{\mathbf{P}}_{m}(f, M)\right]^{2}\right\} ; \\
f_{m}^{\max } \rightarrow f_{\gamma}^{\max } &
\end{aligned}
$$

then the spectrum of the BPF output signal $\tilde{\mathbf{S}}_{m}(T)$ most closely matches the spectrum of the sought gamma activity patterns.

\section{Criterion function and algorithm of search for gamma activity epochs}

Within the reconstructed narrow-band component $\tilde{\mathbf{S}}_{m}(T)$, the search for epochs with gamma activity patterns can be based on the comparison of two adjacent non-overlapping time samples $N$ and $N+1$ (where $N=1,2, \ldots, K / n$ is the sample number), equal in volume and each containing $n<<K$ similar on time counts $\left\{\left(\tilde{s}_{m}\right)_{j, k}\right\}_{k=(N-1) \times n}^{N \times n}$ and $\left\{\left(\tilde{s}_{m}\right)_{j, k}\right\}_{k=N \times n}^{(N+1) \times n}$ from each $j^{\text {th }}$ channel. If a pattern is present in any of these samples, this fact should be reflected by a corresponding criterion function. Thus, with the resolution of $n$ counts, you can determine the time boundaries of a pattern beginning or end. The choice of a criterion function is determined by the choice of a metric. For example, Hausdorff distance (HD) $d_{H}$ [19-21] is used quite efficiently for the purposes of this kind. We will use this metric here.

The algorithm for search and time-axis localization of epochs containing low-amplitude narrow-band BEA patterns will finally be as follows.

1. On the sampling interval $T$ with a sampling frequency $f_{s}$ on $J$ channel in array, we observe BEA $\mathbf{S}(T)=\left(\begin{array}{llll}\left\{s_{1, k}\right\}_{k=1}^{K} & \left\{s_{2, k}\right\}_{k=1}^{K} & \cdots & \left\{s_{J, k}\right\}_{k=1}^{K}\end{array}\right)^{\mathrm{T}}$, which

is a multivariate time series of the dimension $J \times K$. The interval $T$ is chosen to satisfy the hypothesis that the frequency characteristics of the sought patterns are stationary. Then we calculate the current modal frequency $f_{\gamma}^{\max }(T)$ of the gamma activity pattern.

2. With MSSA technique and a solution of the optimization problem (6), from the original record we extract a narrow-band signal $\tilde{\mathbf{S}}_{m}(T)$ of the same dimension $J \times K$ counts, whose spectrum most closely matches the spectrum of the sought patterns.

3. The multidimensional series $\tilde{\mathbf{S}}_{m}(T)$ is divided into $K / n$ non-overlapping time samples of the same dimensions $J \times n$, and for all the adjacent time samples the Hausdorff distance $d_{H}$ is calculated. The size $n<<K$ of the sliding time window is chosen so that the a priori known duration of the gamma ac- tivity pattern is guaranteed to exceed the value of $n \Delta t$. Then, if any of the adjacent samples contains an initial or final pattern border, the criterion function $d_{H}$ will have a local maximum.

4. Next, the subsequent $K$ measurements of the BEA $\mathbf{S}(T)$ are accumulated on the same interval $T$, and the algorithm is repeated.

\section{Experiments on rats}

The experiments are carried out on sexually mature adult rats about 10 months old and $300-400 \mathrm{~g}$ of weight, under xylazin-zoletil anesthesia at the rate of 0.6 and $30 \mathrm{mg} / \mathrm{kg}$ respectively. 10-14 days before the experiment, in the course of a surgical operation, $J=16$ microelectrodes are implanted into their olfactory analyzer structures. The microelectrodes are made of glass-insulated tungsten alloy with a tip diameter of about $5 \mu \mathrm{m}$ and resistance $0.5 \mathrm{M} \Omega$. The BEA is recorded with respect to two reference electrodes which are microscrews in the skull bones. The microelectrode matrix is fixed with six $0.7 \mathrm{~mm}$ bolts screwed into the skull bones.

The experiments are started after a complete postoperative rehabilitation of the animal. Under anesthesia, it is placed in a shielding chamber eliminating background electromagnetic interference. The BEA is recorded by a 32-channel MAP (Multichannel Acquisition Processor) from Plexon Inc. with a recording frequency of $10 \mathrm{KHz}$. After that, the records are decimated by a factor of 10 to the sampling frequency $f_{s}=1 \mathrm{KHz}$. The duration of the experiment is about 2 hours, during which the 16-channel BEA is continuously recorded. Olfactory stimuli are given by spraying various odorants at the animal's nose. After the experiments are completed, the animal is carried back to the vivarium for recovery.

Two time samples of BEA were obtained during the same experiment but at its different stages and their fragments for some of the $J=16$ channels are shown in Fig. 1, $a$ and $b$. Each time sample contains 4 patterns associated with the activity of the olfactory system structures. The graphs of $d_{H}$ search functions calculated using the developed BPF or using the Butterworth BPF (BBPF) for the both time samples of BEA are shown at the same figures. The interval for analysis and the sliding time window size are chosen equal to $T=6 \mathrm{~s}, n=100 \mathrm{~ms}$.

\section{Results and conclusions}

Figure 1 shows that the sought patterns are masked by spontaneous oscillations of the gamma rhythm range and by high-amplitude alpha and beta rhythms similar in their frequency spectra and 
a)
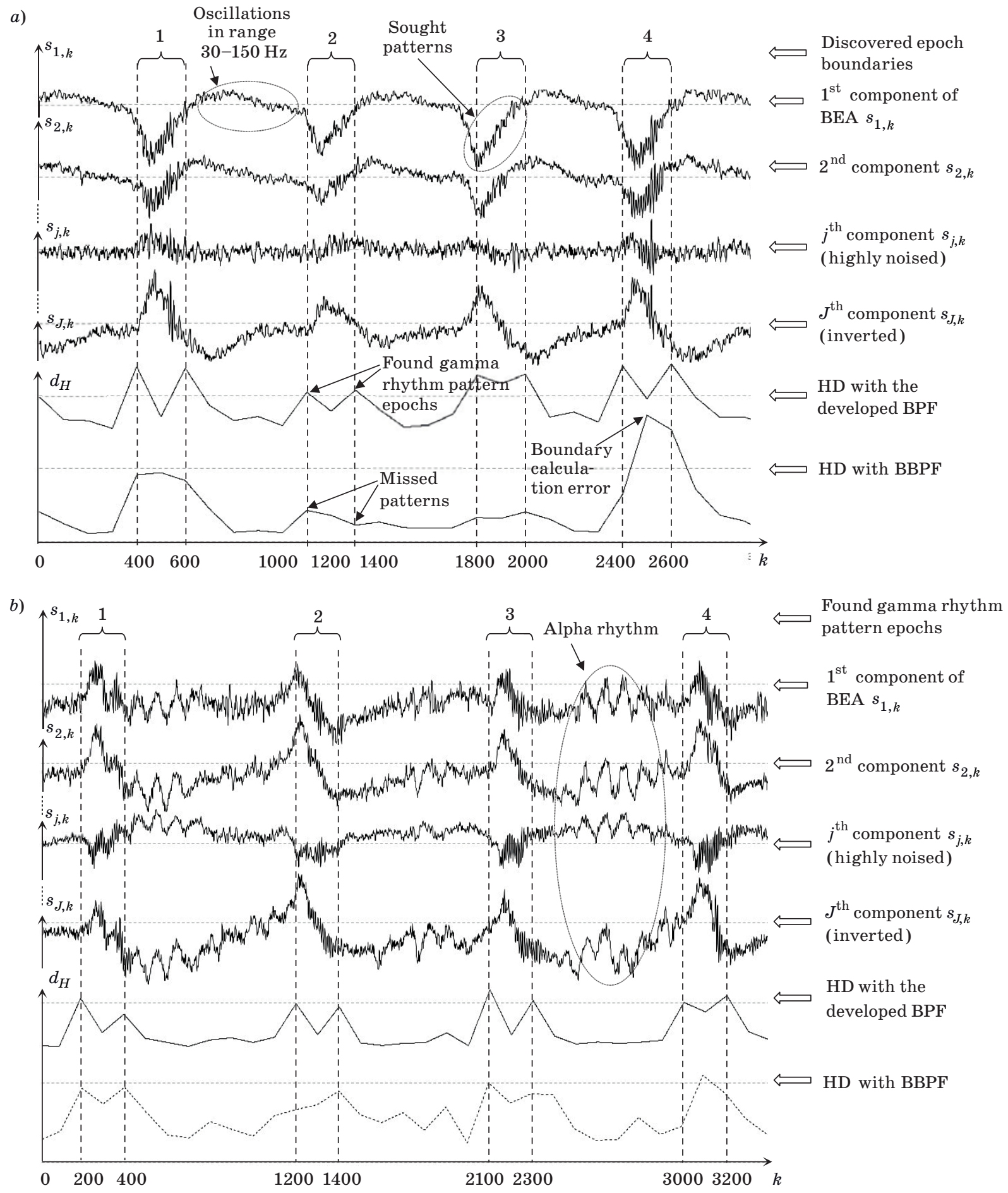

Fig. 1. Two time samples $(a)$ and $(b)$ of the bioelectric activity of an olfactory bulb and Hausdorff distances using BPF and BBPF calculated for the both samples

unrelated to the olfactory system activity. These facts, as well as the inversion of the multichannel BEA signal in some channels, explain the low sensitivity of the search function.

The research has confirmed that the use of bandpass filters with parameters unchanged during the experiment does not provide an effective search, because the frequency characteristics of the sought patterns are non-stationary in time. For example, in Fig. 1 (the graphs "HD with BBPF") you can see that when the BBPF is used in the search algorithm, there are gaps in patterns, and errors in determining the epoch boundaries. BBPF parameters (its order and cut-off frequencies) were chosen in the 
beginning of the experiment. The "best on average" BBPF in the experiment under discussion, using which the time boundaries of the gamma rhythm patterns were found with the least number of errors, had an order 6 with cut-off frequencies 50 and $120 \mathrm{~Hz}$.

For the two samples of the original BEA shown in Fig. 1, $a$ and $b$ we calculated PS function $\mathbf{P}(f)$. In Fig. 2, $a$ the solid line shows the graph of PS function calculated for the time sample of the BEA from Fig. 1, $a$ and in Fig. 2, $b$ the solid line shows the graph of the same PS function calculated for the time sample of the BEA from Fig. 1, b. The graphs show the PS components caused by the above-mentioned spontaneous gamma rhythms which are not associated with the olfactory system activity. It can also be seen how much, during the same experiment, the modal frequencies $f_{\gamma}^{\max }(T)$ of odor-induced patterns differ, equal to 106 and $83 \mathrm{~Hz}$ respectively for the considered time samples.

On the other hand, the use of a developed adaptive BPF provides a reliable automatic search for odor-induced patterns (see, for example, the graphs "HD with the developed BPF" in Fig. 1). The time boundaries of the gamma rhythm epochs are determined with an accuracy not worse than $0.5 n \Delta t$. Algorithm failures in the experiments are observed only in cases of motor artifacts, which significantly distort the BEA records and are usually excluded from the analysis.

The obtained effect can be explained by the fact that a developed BPF provides filtering of $\mathbf{S}(T)$ so that the output signal $\tilde{\mathbf{S}}_{m}(T)$ has a spectrum on the analyzed time sample which most closely matches the current spectrum of the sought patterns. In Fig. 2, $a$ the dotted line shows the graphs of PS function $\tilde{\mathbf{P}}_{m}(f)$ calculated for the BEA from Fig. 1, $a$ and in Fig. 2, $b$ the dotted line shows the graphs of the same function calculated for the BEA from Fig. 1, b. You can see that the developed BPF adjusts itself to the current spectrum of odor-induced patterns and excludes the signal components unre- lated to the olfactory system activity. Due to this, the search function has the required sensitivity.

A final conclusion can be drawn that the developed method provides a reliable real-time automatic search for the time boundaries of odor-induced patterns in a recorded BEA of an OB. The method can be used in the studies of information coding in an animal's olfactory system.

\section{Appendix. $M S S A$ algorithm}

1. By a measured multidimensional time series $\mathbf{S}=\left(\left\{s_{1, k}\right\}_{k=1}^{N_{k}} \quad\left\{s_{2, k}\right\}_{k=1}^{N_{k}} \cdots \quad \cdots \quad\left\{s_{J, k}\right\}_{k=1}^{N_{k}}\right)^{\mathrm{T}}$ of the dimension $\operatorname{dim}(\mathbf{S})=J \times N_{k}$, you build a block trajectory matrix

$$
\mathbf{X}=\left(\begin{array}{llllll}
X_{1} & X_{2} & \ldots & X_{j} & \ldots & X_{J}
\end{array}\right),
$$

where

$$
X_{j}=\left(\begin{array}{cccccc}
s_{j, 1} & s_{j, 2} & \ldots & s_{j, k} & \ldots & s_{j, K} \\
s_{j, 2} & s_{j, 3} & \ldots & s_{j, k+1} & \ldots & s_{j, K+1} \\
\vdots & \vdots & \ddots & \vdots & \ddots & \vdots \\
s_{j, M} & s_{j, M+1} & \ldots & s_{j, M+k} & \ldots & s_{j, N_{k}}
\end{array}\right)
$$

is a Hankel matrix of the $\operatorname{dimension} \operatorname{dim}\left(X_{j}\right)=M \times K$, built for each $j^{\text {th }}$ component separately; $M$ is the caterpillar length (embedding dimension); $K=$ $=N_{k}-M+1$.

2. You calculate the restored matrix

$$
\tilde{\mathbf{X}}(T)=\sum_{m=1}^{M} \tilde{\mathbf{X}}_{m}(T),
$$

where

$$
\begin{gathered}
\tilde{\mathbf{X}}_{1}=\left(\begin{array}{llll}
\tilde{X}_{1,1} & \tilde{X}_{1,2} & \ldots & \tilde{X}_{1, J}
\end{array}\right), \\
\tilde{\mathbf{X}}_{2}=\left(\begin{array}{llll}
\tilde{X}_{2,1} & \tilde{X}_{2,2} & \ldots & \tilde{X}_{2, J}
\end{array}\right), \ldots . \\
\tilde{\mathbf{X}}_{M}=\left(\begin{array}{llll}
\tilde{X}_{M, 1} & \tilde{X}_{M, 2} & \ldots & \tilde{X}_{M, J}
\end{array}\right)
\end{gathered}
$$

a)

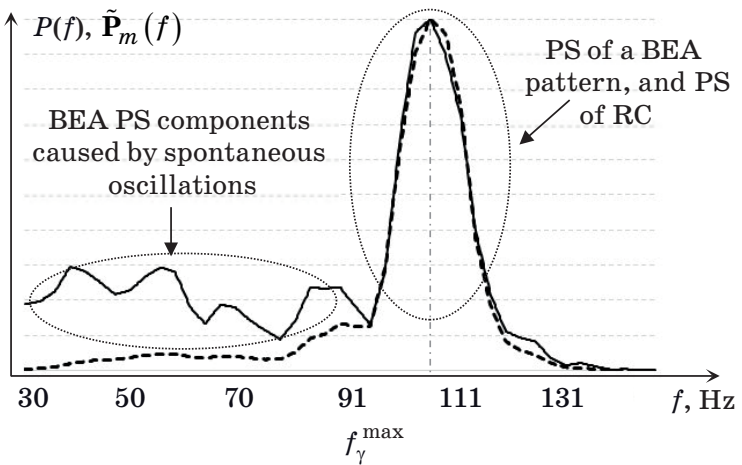

b)

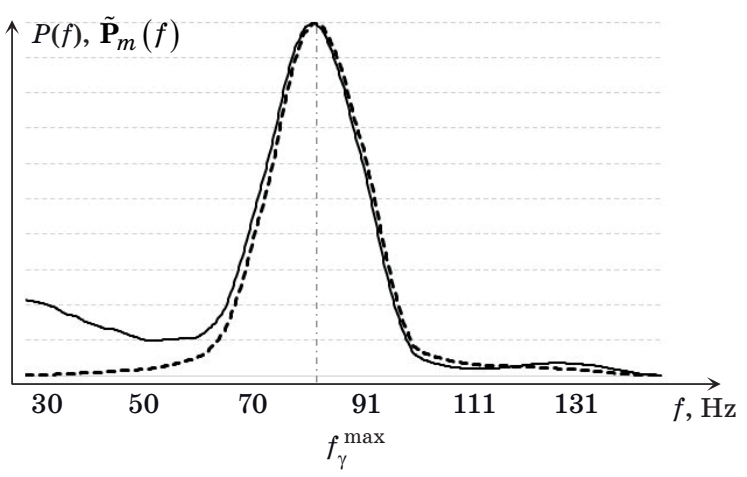

Fig. 2. Functions $\mathbf{P}(f)$ (solid lines) and $\tilde{\mathbf{P}}_{m}(f)$ (dashed lines) both calculated for the bioelectric activity shown in Fig. 1, $a(a)$ and for the bioelectric activity shown in Fig. 1, $b(b)$ 
are block Hankel matrices generated by the corresponding eigenvectors $V_{m}$ of an averaged sample correlation matrix $\mathbf{C}=1 / K\left(\mathbf{X X}^{\mathrm{T}}\right) ; \mathbf{V}=\left(V_{1} \cdots\right.$ $\left.V_{m} \ldots V_{M J}\right)$ is an orthogonal matrix of eigenvectors $V_{m}\left(\operatorname{dim}\left(V_{m}\right)=(M J) \times 1\right)$ of the matrix $\mathbf{C}$, built as a result of ordering the eigenvectors $V_{m}$ in descending order of their eigenvalues $\lambda_{1} \geq \lambda_{2} \geq \ldots \geq \lambda_{M J} \geq 0$; $\mathbf{C}=\mathbf{V} \Lambda \mathbf{V}^{\mathrm{T}}$ is a singular value decomposition of the matrix $\mathbf{C} ; \Lambda=\operatorname{diag}\left(\lambda_{1} \lambda_{2} \ldots \lambda_{M J}\right)$ is a diagonal matrix of eigenvalues. The blocks $X_{m, j}$ of the restored matrices from (A.2) are calculated as follows:

$$
\tilde{X}_{1,1}(T)=\left(\begin{array}{c}
v_{1,1} \\
v_{2,1} \\
\vdots \\
v_{M, 1}
\end{array}\right) \cdot\left(\begin{array}{c}
p_{1,1} \\
p_{2,1} \\
\vdots \\
p_{K, 1}
\end{array}\right)^{\mathrm{T}} ; \ldots
$$

\section{References}

1. Zhuang L., Zhang B., Qin Z., Wang P. Nasal respiration is necessary for the generation of $\gamma$ oscillation in the olfactory bulb. Neuroscience, 2019, no. 398, pp. 218-230. https://doi.org/10.1016/j.neuroscience. 2018.12.011

2. Guo T., Zhuang L., Qin Z., Zhang B., Hu N., Wang P. Multi-odor discrimination by a novel bio-hybrid sensing preservingrat's intact smell perception in vivo. Sensors and Actuators B, 2016, no. 225, pp. 34-41. https://doi.org/10.1016/j.snb.2015.11.010

3. Kepecs A., Uchida N., Mainen ZF. Rapid and precise control of sniffing during olfactory discrimination in rats. Journal of Neurophysiology, 2007, no. 98, pp. 205-213. doi:10.1152/jn.00071.2007

4. Carey R. M., Wachowiak M. Effect of sniffing on the temporal structure of mitral/tufted cell output from the olfactory bulb. Journal of Neuroscience, 2011, no. 31, pp. 10615-10626. doi:10.1523/JNEUROSCI. 1805-11.2011

5. Esclassan F., Courtiol E., Thevenet M., Garcia S., Buonviso N., Litaudon P. Faster, deeper, better: the impact of sniffing modulation on bulbar olfactory processing. PLoS ONE, 2012, no. 7, e40927. doi:10. 1371/journal.pone.0040927

6. Kay L. M. Olfactory system oscillations across phyla. Current Opinion in Neurobiology, 2015, no. 31, pp. 141147. https://doi.org/10.1016/j.conb.2014.10.004

7. Sriraam N., Padma Shri T. K. Detection of alcoholic impact on visual event related potentials using beta band spectral entropy, repeated measures ANOVA and k-NN classifier. 2016 International Conference on Circuits, Controls, Communications and Computing (I4C), Bangalore, India, 4-6 Oct. 2016. doi:10. 1109/CIMCA.2016.8053284

8. Ostanin S. A., Filatova E. V. A Virtual Instrument for Spectral Entropy Estimation of Heart Rate. Izves-

$$
\begin{gathered}
\tilde{X}_{1, J}(T)=\left(\begin{array}{c}
v_{M J-M+1, M J-M+1} \\
v_{M J-M+2, M J-M+1} \\
\vdots \\
v_{M J, M J-M+1}
\end{array}\right) \cdot\left(\begin{array}{c}
p_{1, M J-M+1} \\
p_{2, M J-M+1} \\
\vdots \\
p_{K, M J-M+1}
\end{array}\right)^{\mathrm{T}} ; \\
\ldots ; \tilde{X}_{M, J}(T)=\left(\begin{array}{c}
v_{M J-M+1, M J} \\
v_{M J-M+2, M J} \\
\vdots \\
v_{M J, M J}
\end{array}\right) \cdot\left(\begin{array}{c}
p_{1, M J} \\
p_{2, M J} \\
\vdots \\
p_{K, M J}
\end{array}\right)^{\mathrm{T}},
\end{gathered}
$$

where $p_{1,1}, p_{2,1}, \ldots, p_{k, M J}$ are elements of a noncentered principal components matrix.

3. The application of antidiagonal averaging procedures to each of the matrices $\tilde{\mathbf{X}}_{1}, \ldots ., \tilde{\mathbf{X}}_{M}$ (A.2) allows you to form $M$ multidimensional narrow-band RCs $\tilde{\mathbf{S}}_{1}(T), \ldots, \tilde{\mathbf{S}}_{M}(T)$ (1).

tiya Altajskogo gosudarstvennogo universiteta, 2016, no. 1. pp. 45-51 (In Russian). doi:10.14258/izvasu (2016)1-07

9. Raghu S., Sriraam N., Kumar G. P., Hegde A. S. A novel approach for real-time recognition of epileptic seizures using minimum variance modified fuzzy entropy. IEEE Transactions on Biomedical Engineering, 2018, no. 65(11), pp. 2612-2621. doi:10.1109/ TBME.2018.2810942

10. Shcherban I. V., Kirilenko N. E., Shcherban O. G. Effective cost functions for spectrum entropy to search for high-frequency event-related patterns in electrograms with noise. Informatsionno-upravliaiushchie sistemy [Information and Control Systems], 2018, no. 2, pp. 8-17 (In Russian). doi:10.15217/issn16848853. 2018.2.8

11. Shcherban I. V., Kirilenko N. E., Krasnikov S. O. A search method for unknown high-frequency oscillators in noisy signals based on the continuous wavelet transform. Automation and Remote Control, 2019, no. 80, pp. 1279-1287. https://doi.org/10.1134/ S0005117919070051

12. Rodrigues P. C., Mahmoudvand R. A robust approach to singular spectrum analysis. Quality and Reliability Engineering, 2018, no. 34(5549). doi:10.1002/ qre. 2337

13. Danilov D. L., ZHiglyavskij A. A. Glavnye komponenty vremennyh ryadov: metod "Gusenica" [Principal components of time series structure: SSA]. Saint-Petersburg, Presskom Publ., 1997. 308 p. (In Russian).

14. Mahmoudvand R., Rodrigues P. C., Yarmohammadi M. Forecasting daily exchange rates: A comparison between SSA and MSSA. REVSTAT - Statistical Journal, 2019, no. 17(4), pp. 599-616.

15. Hu H., Guo S., Liu R., Wang P. An adaptive singular spectrum analysis method for extracting brain rhythms of electroencephalography. PeerJ, 2017, no. 6, e3474. doi:10.7717/peerj.3474 
16. Zabalza J., Ren J., Wang Z., Marshall S., Wang J. Singular spectrum analysis for effective feature extraction in hyperspectral imaging. IEEE Geoscience and Remote Sensing Letters, 2014, no. 11, pp. 18861890. doi:10.1109/LGRS.2014.2312754

17. Maddirala A. K., Shaik R. A. Motion artifact removal from single channel electroencephalogram signals using singular spectrum analysis. Biomedical Signal Processing and Control, 2016, no. 30, pp. 79-85. doi:10.1016/j.bspc.2016.06.017

18. Maddirala A. K., Shaik R. A. Removal of EOG artifacts from single channel EEG signals using combined singular spectrum analysis and adaptive noise canceler. IEEE Sensors Journal, 2016, no. 16, pp. 8279-8287. doi:10.1109/JSEN.2016.2560219
19. Vizilter Yu. V., Zheltov S. Yu. Similarity measures and comparison metrics for image shapes. Journal of Computer and Systems Sciences International, 2014, vol. 53, no. 4, pp. 542-555. doi:10.1134/ S1064230714040169

20. Mikhaylov I. A. Image recognition using a radial neighborhood method. Computer Optics, 2010, vol. 34, no. 3, pp. 399-407.

21. Taha A., Hanbury A. An efficient algorithm for calculating the exact Hausdorff distance. IEEE Transactions on Pattern Analysis and Machine Intelligence, 2015, vol. 37, no. 11, pp. 2153-2163.

УдК 681.3:612.8

doi:10.31799/1684-8853-2020-5-62-69

\section{Метод автоматического поиска одорологически вызванных паттернов в биоэлектрической активности обонятельной луковицы крысы}

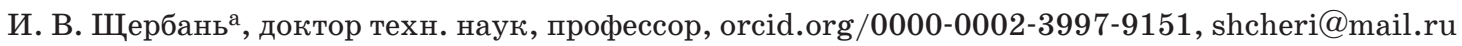

П. О. Косенко а, канд. биол. наук, orcid.org/0000-0002-4333-5332

О. Г. Щербань ${ }^{\text {, }, ~ к а н д . ~ т е х н . ~ н а у к, ~ д о ц е н т, ~ o r c i d . o r g / 0000-0001-5139-8520 ~}$

П. В. Лобзенко ${ }^{б}$, канд. техн. наук, доцент, orcid.org/0000-0002-5293-0109

ажный федеральный университет, Б. Садовая ул., 105/42, Ростов-на-Дону, 344006, РФ

${ }^{6}$ Московский технический университет связи и информатики, Народного Ополчения ул., 32, Москва, 123423, РФ

Введение: изучение обонятельной системы в хронических экспериментах на животных проводится по записям биоэлектрической активности, регистрируемой с использованием микроэлектродных матриц, расположенных на дорзальной поверхности обонятельной луковицы. Считается, что ответная на предъявление одоранта биоэлектрическая активность обонятельной луковицы связана с колебаниями, синхронизированными дыханием и относящимися к диапазону так называемых гамма-ритмов. Цель: разработать метод автоматического поиска временных границ подобных одорологически вызванных паттернов гамма-ритмов в биоэлектрической активности обонятельной луковицы. Результаты: сложности автоматического поиска одорологически вызванных паттернов обусловлены маскированием их спонтанными осцилляциями гамма-ритмов, не связанными с деятельностью обонятельной системы. Кроме того, модальная частота паттернов априорно неизвестна и динамически изменяется в ходе эксперимента, в частности, на наркотизированном животном. В качестве критериальной функции поиска использована метрика Хаусдорфа. В целях увеличения ее чувствительности на основе аппарата многомерного сингулярного спектрального анализа синтезирован адаптивный полосовой фильтр, полоса пропускания которого на анализируемой временной выборке максимально соответствует спектру искомых паттернов. Представлены результаты экспериментов на крысах. Применение полосовых фильтров на основе преобразования Фурье с неизменяемыми в ходе эксперимента параметрами в силу нестационарности во времени частотных характеристик искомых паттернов не обеспечивает эффективного их поиска. Так, при использовании в алгоритме поиска полосового фильтра Баттерворта наблюдались значительные ошибки в определении границ временных эпох паттернов, пропуски паттернов. Использование же синтезированного адаптивного полосового фильтра обеспечило надежный автоматический поиск паттернов и определение их временных границ с высокой точностью. Сбои алгоритма в этом случае наблюдались лишь при двигательных артефактах крыс. Практическая значимость: разработанный метод расширяет существующий инструментарий, применяемый для изучения обонятельной системы живого организма.

Ключевые слова - обонятельная луковица, биоэлектрическая активность, одорологически вызванные паттерны, метрика Хаусдорфа, многомерный сингулярный спектральный анализ.

Для цитирования: Shcherban I. V., Kosenko P. O., Shcherban O. G., Lobzenko P. V. Method of automatic search for odor-induced patterns in bioelectric activity of a rat olfactory bulb. Инфорлационно-управляющие систель, 2020, № 5, с. 62-69. doi:10.31799/1684-88532020-5-62-69

For citation: Shcherban I. V., Kosenko P. O., Shcherban O. G., Lobzenko P. V. Method of automatic search for odor-induced patterns in bioelectric activity of a rat olfactory bulb. Informatsionno-upravliaiushchie sistemy [Information and Control Systems], 2020, no. 5, pp. 62-69. doi:10.31799/1684-8853-2020-5-62-69 